\title{
Infrared Thermography of Neurosurgical Bone Grinding: Determination of High-Speed Cutting Range in Order to Obtain The Minimum Thermal Damage
}

Ehsan Shakouri ( $D$ e_shakouri@iau-tnb.ac.ir)

Islamic Azad University Tehran North Branch https://orcid.org/0000-0002-1882-8450

Pezhman Ghorbani

Islamic Azad University Tehran North Branch

Original Article

Keywords: Skull base neurosurgery, Grinding, Thermal damage, Infrared thermography, High-speed cutting

Posted Date: February 8th, 2021

DOl: https://doi.org/10.21203/rs.3.rs-162850/v1

License: (c) (1) This work is licensed under a Creative Commons Attribution 4.0 International License. Read Full License 


\section{Abstract}

One of the main challenges in skull base tumor removal is the thermal damages that occur in response to grinding the skull bone. During this process, temperature rise occurs at the site of bone grinding, and may cause irreversible thermal damage to the bone, nerves, and arteries. The aim of the present research is to study temperature changes during high-speed grinding of bone via infrared thermography to determine the threshold of high-speed cutting range (HSC-range) in order to achieve the minimum temperature rise and minimize the resulting thermal damages. Experimental tests have been performed in 75 states using the parameters of cutting speed ( 25 states) and feed rate (3 states) on bovine femur samples. The temperature changes of bone have been measured through infrared thermography. The results indicated that temperature rise had a direct relationship with the tool feed rate. Further, the cutting speed of 250 m. min $^{-1}$ at different feed rates was the HSC-range threshold, after which a descending trend of temperature rise emerged; each led to the minimum temperature rise and beyond HSC-range, the temperature rise found an ascending trend. Thus, in order to reduce the thermal damage in neurosurgical bone grinding, the following parameters are suggested as follows: cutting speed $350-425 \mathrm{~m}^{-\mathrm{min}^{-1}}$ for the feed rate $20 \mathrm{~mm} \cdot \mathrm{min}^{-1}\left(\Delta T=4.8-8.5^{\circ} \mathrm{C}\right)$; cutting speed $500-550 \mathrm{~m} \cdot \mathrm{min}^{-1}$ for the feed rate $30 \mathrm{~mm} \cdot \mathrm{min}^{-1}$ $\left(\Delta T=7.2-9 \cdot 3^{\circ} \mathrm{C}\right)$, and cutting speed $650-675 \mathrm{~m} \cdot \mathrm{min}^{-1}$ for the feed rate $40 \mathrm{~mm} \cdot \mathrm{min}^{-1}\left(\Delta T=10-12.5^{\circ} \mathrm{C}\right)$.

\section{Introduction}

Bone grinding using a high-speed (about $60000 \mathrm{r} \cdot \mathrm{min}^{-1}$ ) spherical diamond bur (with a diameter of less than $4 \mathrm{~mm}$ ) is a prevalent procedure in the expanded endonasal approach to the skull base for brain cancer treatments $[17,19,20,22,23]$. This endoscopic approach uses the nose as a natural corridor to operate on the skull base, craniocervical junction, and the brain to both approach and resect tumors with minimal disturbance to surrounding tissues [20]. This minimally invasive technique provides a direct and easy access to tumors in the skull base, avoids facial and scalp incisions, and reduces the need to surgically remove normal tissue $[17,19]$. Similar to other machining processes, large amount of the energy applied to grinding operation is converted to heat. The heat generated during neurosurgical bone grinding propagates through the bone to the adjacent nerves and blood vessels and leads to an increase in temperature [23]. The temperature rise of the bone, nerve, and artery can cause three types of heatrelated injuries: Firstly, bone thermal necrosis typically starts when the temperature rises beyond a critical value of $50{ }^{\circ} \mathrm{C}$; secondly, nerves are vulnerable to the elevated temperature. Depending on the type of nerve, the critical temperature for initiation of the thermal damage could start at $43^{\circ} \mathrm{C}$; thirdly, blood coagulation in the carotid artery due to the temperature rise caused by bone grinding is a major reason for stroke during this neurosurgical procedure $[13,17,19,20,22,23]$. The grinding thermal damage of the bone adjacent to nerves is a side effect with a high probability of occurrence. Incidence of facial nerve paralysis during neurosurgical bone grinding has been reported in more than $3.6 \%$ of cases [1].

Since the heat generation and temperature rise are unavoidable side effects of the bone grinding and may lead to temperature-dependent irreversible damages, neurosurgical bone grinding and achieving 
desired conditions regarding the minimum level of temperature rise have been under investigation by many researchers. Since thermal damage to nerves begin at around $43^{\circ} \mathrm{C}$, assuming $37^{\circ} \mathrm{C}$ for the body, the allowable temperature rise range of the bone grinding operation will be at most around $6{ }^{\circ} \mathrm{C}(\Delta T \leq 6$ ${ }^{\circ} \mathrm{C}$ ). Accordingly, some studies have been performed on predicting temperature rise during the skull base grinding $[17,20]$, developing thermal model in bone grinding [23], examining the effect of mist cooling on reducing the bone temperature rise [22], monitoring thermal changes of the bone during grinding operation [19], infrared thermography of high-speed grinding of bone [13], as well as evaluation of force, torque, and bone quality during grinding [2]. In spite of the attempts made in past research, the obtained results have been far away from the allowable range of temperature rise $\left(\Delta T \leq 6^{\circ} \mathrm{C}\right)$, and incidence of thermal damages still threatens neurosurgical bone grinding. The main cause of heat generation and high temperature rise is the application of high rotational speeds for the bur; this is because in spite of the adjustability of the rotational speed, surgeons prefer to use the full rotational speed (around 60000 r. $\mathrm{min}^{-1}$ ) in order to achieve better stability during the chip removal [20]. Implementation of the bone grinding at high cutting speeds generally leads to considerable heat generation. In this regard, Hosono et al. in high-speed cutting of bone using a diamond bur with a diameter of $5 \mathrm{~mm}$ reported temperature of $174{ }^{\circ} \mathrm{C}$ as well as detection of considerable thermal damage to the neighboring tissue in spinal surgery [7]. Even when applying extensive irrigation in bone grinding, again considerable heat is generated [19]. This is because application of higher rotational speeds and the confined surgical space, reduce the efficiency of saline for cooling and lubrication of the site of grinding, and prevent effective heat dissipation [17]. Thus, the only effective way to reduce the temperature rise during the bone grinding as well as to minimize the risk of thermal damages resulting from that is comprehensively examining this process and precisely determining the optimal process conditions regarding minimum temperature rise.

In order to accurately examine temperature rise in neurosurgical bone grinding, two principal points should be considered: Firstly, the specific cutting energy in grinding is higher than in other machining processes, and a major part of this energy emerges as heat across the workpiece surface [3]; secondly, the low thermal conductivity coefficient of the bone $\left(0.38-2.3 \mathrm{~W} \cdot \mathrm{m}^{-1} \cdot \mathrm{K}^{-1}\right)$ causes the heat not to be dissipated rapidly from the bone surface, and its temperature grows locally $[9,12,15,16]$. Based on studies performed on machining process, it has been found that at low cutting speeds, the heat generated in the process as well as its resulting temperature rise are considerable. In these conditions, elevation of the cutting speed can lead to a slight decrease in the temperature of the machining site through improving the conditions of chip formation and evacuation as well as minor reduction of the cutting forces. However, with further elevation of the cutting speed, due to the dramatic increase of friction and lack of significant changes in machining forces, the temperature rise of the tool and the workpiece will again find an ascending trend. This range of cutting speeds is considered conventional machining region. High-speed machining is an advanced technology which has shown considerable reduction of temperature rise on the tool-chip interface by applying cutting speeds 5-10 times larger than the conventional machining region [6]. This unexpected reduction of temperature rise at high cutting speeds has been attributed to different factors such as changes in the chip nature as well as significant reduction of cutting forces. The notable point in this regard is that the threshold of HSC-range is different 
for various machining processes as well as different workpiece materials (Fig. 1). Fig. 1 shows that firstly the grinding process enters the HSC-range at higher speeds compared to other machining processes (beyond the cutting speed $v=100 \mathrm{~m} \cdot \mathrm{min}^{-1}$ ); secondly the lower the strength of the workpiece material, the larger the cutting speeds should be in order to enter the HSC-range. The notable advantage of the highspeed machining technology has set the ground for its application in machining processes associated with orthopedic surgeries (e.g. bone drilling or cutting) as well as neurosurgical surgeries (such as skull base grinding) $[11,13,16,21]$. Nevertheless, one challenge questioning the application of high cutting speeds in machining processes associated with surgery has been the discrepant results and in some cases less desired outcomes compared to conventional machining [13,19-21]. The main challenge in HSC is that its useful application necessitates proper detection of the HSC-range and precise adjustment of cutting speeds. This is because application of high cutting speeds does not guarantee a considerable reduction of temperature rise at the machining site; rather high cutting speeds can effectively reduce temperature rise if they have fallen within the HSC-range. For example, Shakouri and Mirfallah In a study on neurosurgical bone grinding indicated that the bone temperature rise had a direct relationship with the bur rotational speed, where the rotational speed $45000 \mathrm{r}_{\mathrm{min}}{ }^{-1}$ caused a less temperature rise compared to 55000 and $65000{\mathrm{r} . \mathrm{min}^{-1}}^{-1}$ [13]. On the other hand, in a comprehensive study performed by Shakouri et al. on high-speed drilling of bone, it was found that the cutting speed $49.42 \mathrm{~m} \cdot \mathrm{min}^{-1}$ (equal to the rotational speed $5000 \mathrm{r} \cdot \mathrm{min}^{-1}$ for a drill bit with diameter $3.2 \mathrm{~mm}$ ) was the HSC-range threshold and the minimum temperature rise was achieved at the rotational speed $7000 \mathrm{r} . \mathrm{min}^{-1}$; Moreover, application of higher speeds (beyond the HSC-range) caused a more severe temperature rise even compared to conventional drilling speeds (Low-speed drilling) $[11,16]$. Having investigated the research conducted on neurosurgical bone grinding, it has been found that in spite of applying high cutting speeds, due to failure to accurately detect HSC-range for this operation, more severe temperature rise has occurred in the bone, which has been far higher than the temperature rise allowable range $\left(\Delta T \leq 6^{\circ} \mathrm{C}\right)$. Based on Fig. 1 , it is observed that the factors that complicate precise determination of HSC-range for bone grinding are the nature of grinding operation and the low tensile strength of the bone, which allow achieving HSC-range only at high cutting speeds (higher than $100 \mathrm{~m} \cdot \mathrm{min}^{-1}$ ).

The aim of the present research is experimental investigation of temperature rise during the bone grinding within an extensive range of cutting speeds through infrared thermography in order to determine HSCrange and to identify the desired cutting speed (at different feed rates) in order to minimize the thermal damage. The innovation of the present research compared to past studies is that so far HSC-range has not been reported for the bone grinding, and this research is the first report on precise determination of the threshold of HSC-range and the desired cutting speed in order to minimize the thermal damage. Note that the results of the present research have been compared with the findings of other studies and then verified.

\section{Materials And Methods}


Since the aim of the present research has been investigating the thermal aspects of high-speed grinding of bone, infrared (IR) thermography method has been used in order to measure the bone temperature changes. IR thermography method is one of the non-contact methods of temperature measurement successfully employed in various studies in biomedical engineering $[10,11,13,14]$. Another notable point is that in order to measure temperature during the bone grinding, use of IR thermography is more preferred over contact thermocouple, since the cortical bone region has a greater mineral density and mechanical strength compared to other parts of the bone, and the maximum temperature rise during the machining occurs on its outer surface $[5,10-13,15,16]$. Note that before running the experimental tests, by comparing the results of the IR camera against results obtained from contact thermocouple, the accuracy of the IR camera results has been ensured. The specifications of the IR camera utilized are as follows:

- FLIR C2, USA, Thermal range: -10 to $150^{\circ} \mathrm{C}$, Thermography resolution: 4800 pixels, Heat sensitivity: $0.1{ }^{\circ} \mathrm{C}$, Spectral range: $7.5-14 \mu \mathrm{m}$.

Since the IR camera functions based on radiation heat transfer, accordingly the emissivity coefficient of the surface is very effective in the heat transfer rate (according to the Stefan-Boltzmann law, $j^{*}=\epsilon \sigma T^{4}$, where $j^{*}$ denotes radiant emittance, $\epsilon$ is emissivity coefficient, $\sigma$ shows Stefan-Boltzmann constant, and $T$ represents body's thermodynamic temperature). According to different studies, bone is an exceptional material which has no constant emissivity coefficient $(\epsilon)$; thus different values have been reported for its emissivity coefficient at various temperatures [18], and in some studies an average value has been considered for it. In the present research, according to the study by Feldmann and Zysset, for temperature changes up to $60^{\circ} \mathrm{C}$, the emissivity coefficient has been considered $\epsilon=0.96$, and for temperature changes up to $80^{\circ} \mathrm{C}$, this coefficient has been considered $\epsilon=0.97$ [4]. Before running the experimental tests, the IR camera has been placed on a special pod $50 \mathrm{~cm}$ away from the surface of the bone sample. It was then connected to the computer using a connecting cable so that the operator could perform the temperature monitoring throughout the process. In order to provide an extensive range of rotational speeds for bur, a high-speed induction motor (Arel TIP: ARFM $1 Y-M 3$ ) has been used with the maximum rotational speed of $18000 \mathrm{r} \cdot \mathrm{min}^{-1}$. Further, in order to achieve a wide range of cutting speeds during the bone grinding, a grinding wheel (bur) with a diameter of $12.31 \mathrm{~mm}$ made of diamond has been employed. Fig. 2 displays the schematic of the equipment utilized in the experimental tests.

\section{Sample preparation}

The bone samples utilized in the grinding tests have been fresh bovine femurs with the approximate age of 24 months provided from a local abattoir and utilized after some hours following extraction from the body. Note that no animal was sacrificed specifically for conducting the tests in this research. The bovine femur was chosen because of its maximum similarity to the human bone in terms of mechanical properties $[9-12,15,16]$. It has also been studied in previous research associated with the bone grinding $[13,17,19,20,22,23]$. In order to ensure the constancy of the depth of cut during the high-speed grinding, 
the external surface of the mid-shaft of the bovine femoral diaphysis became smooth and flat by the pregrinding operation.

\section{Methodology}

Considering the relationship between the cutting speed and rotational speed of the tool, $v=\pi D N$ (where, $v$ represents cutting speed, $D$ is tool diameter, and $N$ denotes the rotational speed of the tool), it is evident that achieving an extensive range of cutting speeds $(v)$ can be possible through applying a high diameter bur as well as applying high rotational speeds. In order to study the temperature changes during the highspeed grinding of bone, the major parameters of the process, including the cutting speed and feed rate have been considered as the input parameters. Based on the literature review and considering the set of process conditions utilized in other studies (Table 1), the values of cutting speed, feed rate, and depth of cut were set for the experimental tests in the present research (Table 2).

Accordingly, the tests were designed in 25 states for cutting speed, 3 states for the feed rate, and one state for the depth of cut. Totally 75 experimental states have been examined (without using any coolant fluid). Note that due to reduction of the effect of the phenomenon of ploughing, to ensure the complete bone cutting, and to further differentiate between the temperature results, $0.75 \mathrm{~mm}$ has been considered for depth of cut; according to Table 1, it is slightly larger than the average depth of cut examined in previous research $(d=0.1-1.0 \mathrm{~mm})$. The length of the path of bone grinding has been chosen $20 \mathrm{~mm}$ and the feeding direction has been selected as forward grinding type. Changes in the feed rate as well as adjustment of the depth of cut in this research have been performed using designed CNC table. Note that all tests have been replicated at least three times, and the mean value of the results has been considered for each state. Since the initial temperature of the bone sample is not very important and the room temperature does not cause changes in the temperature difference occurring during the bone grinding [13], all grinding tests have been performed at room temperature. As in the present research the temperature rise in the bone sample has been of interest, by calculating the difference between the measured temperature and the baseline level temperature (initial temperature of the bone sample), $\Delta T$ has been calculated. Fig. 3 depicts the stages of implementing experimental tests of high-speed grinding of bone.

\section{Results}

After conducting the high-speed grinding of bone tests within an extensive range of cutting speeds (100$700 \mathrm{~m}^{\mathrm{min}} \mathrm{m}^{-1}$ ) and measuring the temperature changes of the bone via IR camera, the temperature rise value has been recorded for each cutting speed (in relation to the baseline level temperature). Fig. 4 presents some samples of thermographic images of the bone grinding (Fig. 4-a and b for feed rate 20 $\mathrm{mm} \cdot \mathrm{min}^{-1}$, Fig. 4-c and $d$ for the feed rate $30 \mathrm{~mm} \cdot \mathrm{min}^{-1}$, and Fig. 4-e and $\mathrm{f}$ for the feed rate $40 \mathrm{~mm} \cdot \mathrm{min}^{-1}$ ). The results of bone temperature changes at various cutting speeds have also been presented in Figs. 5-7 for feed rates 20,30 , and $40 \mathrm{~mm} \cdot \mathrm{min}^{-1}$. Based on Figs. 5-7, it is observed that for all three feed rates 20 , 30 , and $40 \mathrm{~mm} \cdot \mathrm{min}^{-1}$, with increase in the cutting speed from 100 to $250 \mathrm{~m} \cdot \mathrm{min}^{-1}$, the extent of bone 
temperature rise has increased (Region (II)). However, beyond the cutting speed $250 \mathrm{~m}^{\mathrm{min}}{ }^{-1}$, a range of cutting speeds has started, in which the temperature rise $(\Delta T)$ had a descending trend and culminated in the minimum temperature rise. Thus, $v=250 \mathrm{~m} \cdot \mathrm{min}^{-1}$ can be considered the HSC-range threshold for bone grinding. In other words, Region (II) in Figs. 5-7 is the HSC-range for bone grinding, as can be seen, it has resulted in the minimum temperature rise throughout the entire range of cutting speeds $\left(\Delta T=4.8^{\circ} \mathrm{C}\right.$ for $f=$ $20 \mathrm{~mm} \cdot \mathrm{min}^{-1}, \Delta T=7.2^{\circ} \mathrm{C}$ for $f=30 \mathrm{~mm} \cdot \mathrm{min}^{-1}$, and $\Delta T=10^{\circ} \mathrm{C}$ for $\left.f=40 \mathrm{~mm} \cdot \mathrm{min}^{-1}\right)$. Another notable point is that the minimum temperature rise developed at the end of the HSC-range at the feed rate $20 \mathrm{~mm} \cdot \mathrm{min}^{-1}$ has fallen exactly within the $\Delta T \leq 6^{\circ} \mathrm{C}$ allowable range; also, $\Delta T$ for the feed rates 30 and $40 \mathrm{~mm} \cdot \mathrm{min}^{-1}$ is close to the allowable range with an acceptable approximation. After leaving the HSC-range and entering the Region (III), the temperature rise has again found in ascending trend, and elevation of the cutting speed has caused a larger temperature rise in the bone.

Figs. 5-7 indicate that in the bone grinding operation, $\Delta T$ has had a direct relationship with the feed rate $(f)$, an application of higher feed rates has resulted in greater temperature rise; these bone temperature changes have been as follows: $\Delta T=4.8-14.6^{\circ} \mathrm{C}$ at $f=20 \mathrm{~m} \cdot \mathrm{min}^{-1}, \Delta T=7.2-29.2^{\circ} \mathrm{C}$ at $f=30 \mathrm{~m} \cdot \mathrm{min}^{-1}$, and $\Delta T=10-39.5^{\circ} \mathrm{C}$ at $f=40 \mathrm{~m} \cdot \mathrm{min}^{-1}$.

\section{Discussion}

Based on Figs. 5-7, it was observed that in the Region (I), which is considered conventional grinding range (Low-speed grinding), the bone temperature rise $(\Delta T)$ has had a direct relationship with the cutting speed $(v)$, and almost at all feed rates, the maximum temperature rise has been achieved at the end of this range of cutting speeds. To analyze this phenomenon, the factors affected by cutting speed would be examined concurrently:

- The mechanism of chip formation and grinding forces: with the increase in the rotational speed, finer cuts are created in the bone, thereby reducing the volumetric material removal per grit. Accordingly, the required deformation energy as well as the grinding forces will decrease. Thus, from the above aspect, an increase in the cutting speed causes reduced temperature rise [2].

- The chip evacuation velocity: upon elevation of the tool rotational speed, the chip evacuation velocity increases, and due to improved heat transfer rate, the temperature rise of the bone decreases slightly $[11,13]$.

- Friction: upon an increase in the cutting speed of the tool (rotational speed) at a constant feed rate, the number of revolutions of the rotating tool as well as the physical contact of its surface with the bone increase, causing higher friction and intensification of frictional heating. This frictional heating has a direct relationship with cutting speed and causes a further temperature rise of the bone [13].

With the increase in the cutting speed within the Region (I) range, the grinding forces have reached the possible minimum value under conventional machining conditions, and with further elevation of speed, no notable reduction would occur in the amount of machining forces. Further, due to the low thermal 
conductivity of bone, which is in the range of $0.38-2.3 \mathrm{~W} \cdot \mathrm{m}^{-1} \cdot \mathrm{K}^{-1}[15,16]$, the share of heat transfer by chips is limited (unlike metal chips during the drilling which are able to evacuate up to $85 \%$ of the total heat generated in the process thanks to their high heat capacity and high thermal conductivity coefficient [8]), and application of higher speeds would not improve heat evacuation considerably. On the other hand, the heat generated in response to friction is notable, whose value is directly associated with the cutting speed. All of these factors justify the ascending trend of temperature rise upon elevation of the cutting speed within the Region (I) range.

In Region (II) range, as the cutting speed goes beyond $v=250 \mathrm{~m} \cdot \mathrm{min}^{-1}$, the descending trend of temperature rise begins, and the cutting speed of the bone grinding process has entered the HSC-range; thus, $250 \mathrm{~m} \cdot \mathrm{min}^{-1}$ can be considered as the threshold of the HSC-range $\left(v_{H S C}\right)$. The changes occurring in the temperature rise trend within the above range are affected by changes in the nature of the bone chip, formation of powder-shaped chips, facilitation of the chip formation and evacuation conditions, and decline of the machining forces $[11,13]$. At the end of HSC-range, the cutting speed reaches its optimal value regarding development of the minimum temperature rise, and upon leaving the HSC-range and entering the Region (III), the bone temperature rise has experienced an ascending trend again. The notable point in Figs. 5-7 is that the HSC-range has begun for all feed rates from $v_{H S C}=250 \mathrm{~m} \mathrm{~min}^{-1}$, though the extent of this range is directly associated with the feed rate, and for higher feed rates, it has involved a more extensive speed range (Table 3). Since the HSC-range threshold speed is essentially dependent on the shear strength of the material and type of machining process, concurrent beginning of the HSC-range at $v_{H S C}=250 \mathrm{~m} \cdot \mathrm{min}^{-1}$ for different feed rates is absolutely predictable, and suggests independence of $v_{H S C}$ from the feed rate [6]. Nevertheless, based on Figs. 5-7 and Table 3, it is evident that the length of the HSC-range has essentially been dependent on the feed rate, and application of higher feed rates has led to the larger magnitude of the HSC-range. The factor causing the low feed rates to have shorter HSCrange is the frictional interaction between the rotating tool and the bone as well as the heat resulting from friction. As mentioned earlier, upon entering the HSC-range and as the cutting speed goes beyond the $v_{H S C}$ the nature of the bone chip changes, and the incidence of the chip size shrinkage as well as formation of the powder-shaped chip has considerably reduced the grinding forces. All of these factors lead to diminished heat generation in response to the cutting as well as its resulting decreased temperature rise. On the other hand, the elevation of the tool rotational speed will increase its physical contact with the bone surface and frictional heating. Thus, friction is an additional heat source adversely affecting the desired outcomes of speed elevation within HSC-range. Since at low feed rates, the rotating tool crosses over the bone surface at a slower rate, thus the bone surface will be in contact with the rotating tool for a longer time and will undergo greater frictional heating. Accordingly, at low feed rates, the extent of frictional heating will be larger, and the factor of friction overcomes the reduced temperature rise resulting from entering the HSC-range earlier. This causes the range to end more quickly. Conversely, at high feed rates, as the tool crosses over the workpiece surface faster, the frictional heating will be lower and the factor of friction will require a longer time in order to overcome the reduced temperature rise resulting from changes in the chip nature. As a result, ascending the trend of temperature changes will be 
delayed. After leaving the HSC-range and entering the Region (III), due to the predominance of the effect of friction factor, the ascending trend of frictional heating continues, whereby the bone temperature rise has increased.

Another notable point regarding the results in Figs. 5-7 is the direct relationship between temperature rise and the feed rate. In this regard, with elevation of the feed rate, the tool's penetration volume into the bone increases, which requires greater shear energy for chip formation, thus causing higher grinding forces. According to the theory of machining mechanics, application of larger forces would lead to greater heating and elevation of temperature rise [2].

In order to verify the results of the present research, Fig. 8 compares them with the findings obtained by Shakouri and Mirfallah, obtained using air pencil grinder tool [13] (under the same conditions regarding cutting speed and depth of cut). Fig. 8 indicates that changes in the temperature rise have followed a similar trend for both studies. Further, the slight difference between the results of these two studies at various feed rates is due to application of a bur with a larger diameter in the present research, causing increased chip removal volume, increased grinding forces, and more heating.

Based on the results of the present research, it can be deduced that the cutting speed $v_{H S C}=250 \mathrm{~m} \cdot \mathrm{min}^{-1}$ has been the HSC-range threshold for the bone grinding operation, and by applying the optimal cutting speed, lying at the end of the above-mentioned range, the minimum temperature rise can be achieved during surgery, thereby significantly reducing the risk of thermal damages. Hence, as a recommendation for orthopedic surgery and neurosurgery, the values presented in Table 4 are proposed. Note that since application of a bur with an approximate diameter of $4 \mathrm{~mm}$ is common in neurosurgical bone grinding, the rotational speed suitable for diameter of $4 \mathrm{~mm}$ has been calculated in order to achieve the desired cutting speed, and presented in the above table. Concerning the direct relationship between temperature rise and depth of cut [13], and as grinding tests in the present research have been performed with the depth of cut $d=0.75 \mathrm{~mm}$, which is larger than the average prevalent depth of cut during the neurosurgical bone grinding, it can be ensured that in case of applying a smaller depth of cut under the optimal cutting conditions proposed in Table 4, the bone temperature rise would not exceed the allowable range, thereby minimizing the incidence of thermal damages. Further, the authors state that one of the limitations of the present research was the complexity of conducting experimental test on the human skull bone and use of a similar bone (bovine femur). Definitely, running high-speed grinding tests on the human skull bone would lead to more accurate results.

\section{Conclusion}

In the present research, IR thermography of the bone grinding process was performed, and the extent of bone temperature rise was measured under different process conditions, with the following results obtained: 
- The cutting speed $v_{H S C}=250 \mathrm{~m} \cdot \mathrm{min}^{-1}$ was the HSC-range threshold for the high-speed grinding of bone at all feed rates. As the cutting speed increased beyond the $v_{H S C}$, the bone temperature rise diminished until the end of HSC-range.

- The beginning of the HSC-range $\left(v_{H S C}=250 \mathrm{~m} \cdot \mathrm{min}^{-1}\right)$ was dependent on the bone mechanical properties and is independent of the feed rate; however, the end of HSC-range and its extent were dependent on the feed rate due to the effect of friction. Thus, higher feed rates presented a wider HSC-range.

- The bone temperature rise had a direct relationship with the tool feed rate, and contributed to achieving the maximum temperature rise range for the feed rate $40 \mathrm{~mm} \cdot \mathrm{min}^{-1}\left(\Delta T=10-39.5^{\circ} \mathrm{C}\right)$, while the minimum temperature rise range was found for the feed rate $20 \mathrm{~mm} \cdot \mathrm{min}^{-1}\left(\Delta T=4.8-14.6^{\circ} \mathrm{C}\right)$.

- As a recommendation for usage in neurosurgery and orthopedic surgery, in order to achieve the minimum temperature rise in the bone and minimize the thermal damage, the cutting speed 350-425 $\mathrm{m} . \mathrm{min}^{-1}$ is suggested for the feed rate $20 \mathrm{~mm} \cdot \mathrm{min}^{-1}$ (leading to temperature rise $\Delta T=4.8-8.5^{\circ} \mathrm{C}$ ), cutting speed $500-550 \mathrm{~m} \cdot \mathrm{min}^{-1}$ for the feed rate $30 \mathrm{~mm} \cdot \mathrm{min}^{-1}$ (leading to temperature rise $\Delta T=7.2-9.3$ ${ }^{\circ} \mathrm{C}$ ), and cutting speed $650-675 \mathrm{~m} \cdot \mathrm{min}^{-1}$ for the feed rate $40 \mathrm{~mm} \cdot \mathrm{min}^{-1}$ (leading to temperature rise $\left.\Delta T=10-12.5^{\circ} \mathrm{C}\right)$.

\section{Declarations}

Funding information The author(s) received no financial support for the research, authorship, and/or publication of this article.

\section{Compliance with Ethical Standards}

Conflicts of interest/Competing interests The author(s) declared no potential Conflicts of interest/Competing interests with respect to the research, authorship, and/or publication of this article.

Availability of data and material Not applicable.

Code availability Not applicable.

Ethical approval All procedures and methods performed in the current study were in accordance with the Declaration of Helsinki 1964 and its later amendments. The research design and protocol were approved by the ethical standards of Research Committee of the Islamic Azad University-Tehran North Branch.

Consent to participate This article does not contain any studies with human participants/patient data.

Consent for publication This article does not contain any studies with human participants/patient data.

Informed consent This article does not contain any studies with human participants/patient data. 
Authors' contributions All authors contributed to the study conception and design. Material preparation, data collection and analysis were performed by Ehsan Shakouri and Pezhman Ghorbani. The first draft of the manuscript was written by Ehsan Shakouri and all authors commented on previous versions of the manuscript. All authors read and approved the final manuscript.

\section{References}

1. Aslan A, Vatansever HS, Aslan GG, Eskiizmir G, Giray G (2005) Effect of thermal energy produced by drilling on the facial nerve: histopathologic evaluation in guinea pigs. The Journal of Laryngology and Otology 119(8):600-605

2. Babbar A, Jain V, Gupta D (2020) In vivo evaluation of machining forces, torque, and bone quality during skull bone grinding. Proc Inst Mech Eng H 234(6):626-638

3. Boothroyd G, Knight WA (2006) Fundamentals of Metal Machining and Machine Tools. CRC, London, Taylor \& Francis, 3rd Edition

4. Feldmann A, Zysset $P$ (2016) Experimental determination of the emissivity of bone. Med Eng Phys 38:1136-1138

5. Gholampour S, Shakouri E, Deh HHH (2018) Effect of drilling direction and depth on thermal necrosis during tibia drilling: an in vitro study. Technol Health Care 26(4):687-697

6. Grzesik W (2010) Fundamentals of Machining of Metallic Materials. WNT, Warsaw

7. Hosono N, Miwa T, Mukai Y, Takenaka S, Makino T, Fuji T (2009) Potential risk of thermal damage to cervical nerve roots by a high-speed drill. J Bone Joint Surg Br 91(11):1541-1544

8. Karmani S (2006) The thermal properties of bone and the effects of surgical intervention. Current Orthopaedics 20(1):52-58

9. Shakouri E, Abbasi M (2018) Investigation of cutting quality and surface roughness in brasive water jet machining of bone. Proc Inst Mech Eng H 232(9):850-861

10. Shakouri E, Ghorbani Nezhad M (2020) An in vitro study of bone drilling: infrared thermography and evaluation of thermal changes of bone and drill bit. Phys Eng Sci Med 43:247-257

11. Shakouri E, Ghorbani Nezhad M, Ghorbani P, et al (2020) Investigation of thermal aspects of highspeed drilling of bone by theoretical and experimental approaches. Phys Eng Sci Med 43:959-972

12. Shakouri E, Haghighi Hassanalideh H, Gholampour S (2018) Experimental investigation of temperature rise in bone drilling with cooling: A comparison between modes of without cooling, internal gas cooling, and external liquid cooling. Proc Inst Mech Eng H 232(1):45-53

13. Shakouri E, Mirfallah P (2019) Infrared thermography of high-speed grinding of bone in skull base neurosurgery. Proc Inst Mech Eng H 233(6):648-656

14. Shakouri E, Mobini A (2019) Airbag deployment: Infrared thermography and evaluation of thermal damage. Proc Inst Mech Eng H 233(4):424-431

15. Shakouri E, Sadeghi MH, Karafi MR, et al (2015) An in vitro study of thermal necrosis in ultrasonicassisted drilling of bone. Proc Inst Mech Eng H 229(2):137-149 
16. Shakouri E, Sadeghi MH, Maerefat M, et al (2014) Experimental and analytical investigation of the thermal necrosis in high-speed drilling of bone. Proc Inst Mech Eng H 228(4):330-341

17. Shih AJ, Tai BL, Zhang L, Sullivan S, Malkin S (2012) Prediction of bone grinding temperature in skull base neurosurgery. CIRP Annals - Manufacturing Technology 61(1):307-310

18. Stumme LD, Baldini TH, Jonassen A, Bach JM, Golden M, Health C (2003) Proc. Summer Bioengin. Conf. ASME June 25-29. Key Biscayne, USA

19. Tai BL, Zhang L, Wang A, Sullivan S, Shih AJ (2013) Neurosurgical Bone Grinding Temperature Monitoring. Procedia CIRP 5:226-230

20. Tai BL, Zhang L, Wang AC, Sullivan S, Wang G, Shih AJ (2013) Temperature prediction in high speed bone grinding using motor PWM signal. Med Eng Phys 35:1545-1549

21. Udiljak T, Ciglar D, Skoric S (2007) Investigation into bone drilling and thermal bone necrosis. Adv Prod Eng Manag 2(3):103-112

22. Zhang L, Tai BL, Wang AC, Shih AJ (2013) Mist cooling in neurosurgical bone grinding. CIRP Annals Manufacturing Technology 62:367-370

23. Zhang L, Tai BL, Wang G, Zhang K, Sullivan S, Shih AJ (2013) Thermal model to investigate the temperature in bone grinding for skull base neurosurgery. Med Eng Phys 35:1391-1398

\section{Tables}

Table 1 Grinding conditions used in other researches.

\begin{tabular}{|llll|}
\hline Reference & $\begin{array}{l}\text { Rotational speed, } \boldsymbol{N}\left(* 10^{3}\right. \\
\text { r.min } \mathbf{m}^{-1}\end{array}$ & $\begin{array}{l}\text { Feed rate, } \boldsymbol{f} \\
\left(\mathbf{m m} \cdot \mathbf{m i n}^{-1}\right)\end{array}$ & $\begin{array}{l}\text { Depth of cut, } \boldsymbol{d} \\
(\mathbf{m m})\end{array}$ \\
\hline Babbar and Gupta [2] & $35-45-55$ & $20-40-60$ & $0.5-0.75-1.0$ \\
\hline $\begin{array}{l}\text { Shakouri and Mirfallah } \\
\text { [13] }\end{array}$ & $45-55-65$ & $20-30-40$ & $0.25-0.50-0.75$ \\
\hline Shih et al. [17] & 60 & 20 & 0.5 \\
\hline Tai et al. [20] & 60 & $20-40$ & $0.1-0.25-0.4$ \\
\hline Zhang et al. [22] & 75 & 20 & 0.5 \\
\hline Zhang et al. [23] & 60 & 20 & 0.4 \\
\hline
\end{tabular}

Table 2 Cutting parameters of high-speed grinding of bone. 


\begin{tabular}{|c|c|}
\hline Bur diameter, $D(\mathrm{~mm})$ & 12.31 \\
\hline Depth of cut, $d(\mathrm{~mm})$ & 0.75 \\
\hline Feed rate, $f\left(\mathrm{~mm} \cdot \mathrm{min}^{-1}\right)$ & $20-30-40$ \\
\hline Rotational speed, $N\left(\right.$ r.min $\left.{ }^{-1}\right)$ & $2700-18000$ \\
\hline Cutting speed, $v\left(\mathrm{~m} \mathrm{~min}^{-1}\right)$ & $100-700$ (with $25 \mathrm{~m} \cdot \mathrm{min}^{-1}$ intervals) \\
\hline Number of iteration of tests & At least 3 times \\
\hline
\end{tabular}

Table 3 HSC-rang for various feed rates.

\begin{tabular}{|ll|}
\hline Feed rate, $f\left(\mathrm{~mm}_{\mathrm{min}}{ }^{-1}\right)$ & HSC-rang, $\boldsymbol{v}\left(\mathrm{m}_{\mathrm{min}}{ }^{-1}\right)$ \\
\hline 20 & $250-400$ \\
\hline 30 & $250-500$ \\
\hline 40 & $250-650$ \\
\hline
\end{tabular}

Table 4 Optimal grinding conditions in order to obtain minimum thermal damage (Depth of cut, $d=0.75$ $\mathrm{mm})$.

\begin{tabular}{|c|c|c|c|c|c|}
\hline Rank & $\begin{array}{l}\text { Feed rate, } f \\
\left(\mathrm{~mm} \cdot \mathrm{min}^{-1}\right)\end{array}$ & $\begin{array}{l}\text { Cutting } \\
\text { speed, } v \\
\left(\mathrm{~m} \cdot \mathrm{min}^{-1}\right)\end{array}$ & $\begin{array}{l}\text { Rotational } \\
\text { speed, } N \\
(\text { r.min } \\
-1)\end{array}$ & $\begin{array}{l}\text { Temperature } \\
\text { rise, } \Delta T\left({ }^{\circ} \mathrm{C}\right)\end{array}$ & $\begin{array}{l}\text { Recommended rotational speed } \\
\text { for bur with a diameter of } 4.21 \\
\mathrm{~mm}, N\left(\text { r. } \mathrm{min}^{-1}\right)\end{array}$ \\
\hline 1 & 20 & $350-425$ & $\begin{array}{l}9100- \\
11000\end{array}$ & $4.8-8.5$ & $26500-32150$ \\
\hline 2 & 30 & $500-550$ & $\begin{array}{l}13000- \\
14300\end{array}$ & 7.2-9.3 & $37800-41600$ \\
\hline 3 & 40 & $650-675$ & $\begin{array}{l}16900- \\
17500\end{array}$ & $10-12.5$ & $49150-51000$ \\
\hline
\end{tabular}

\section{Figures}


(A)

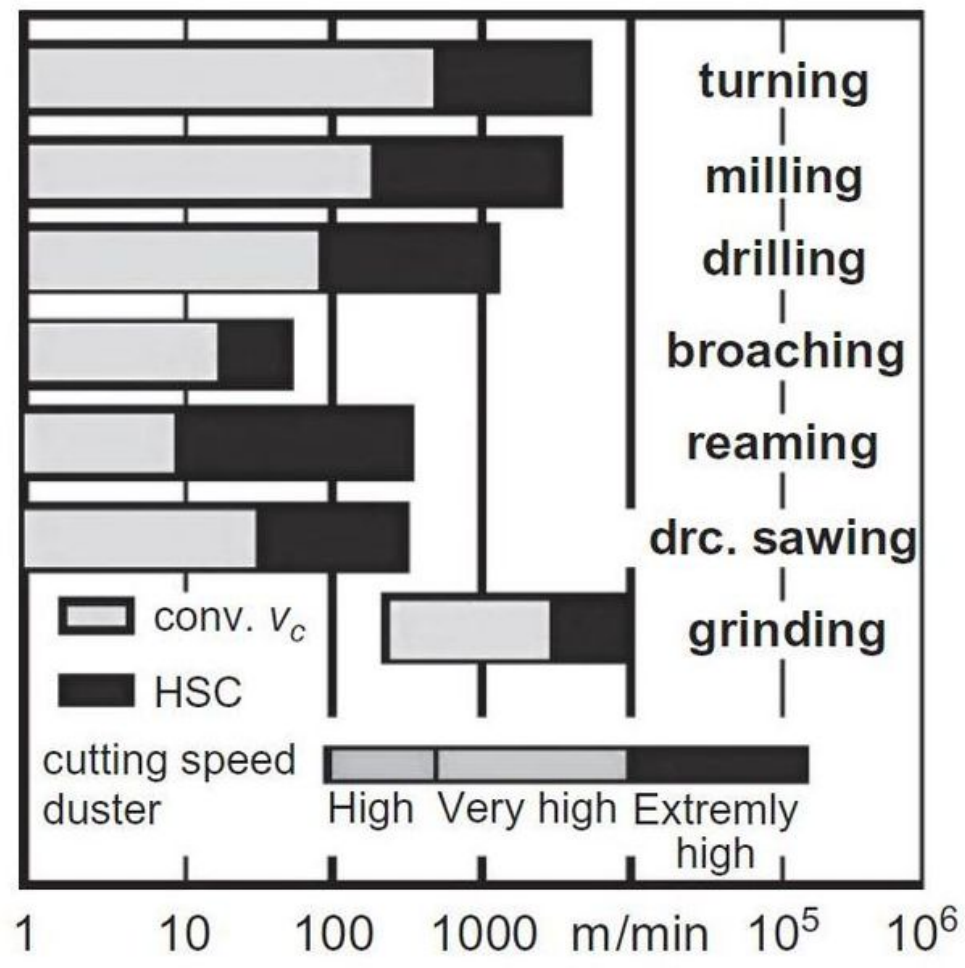

(B)

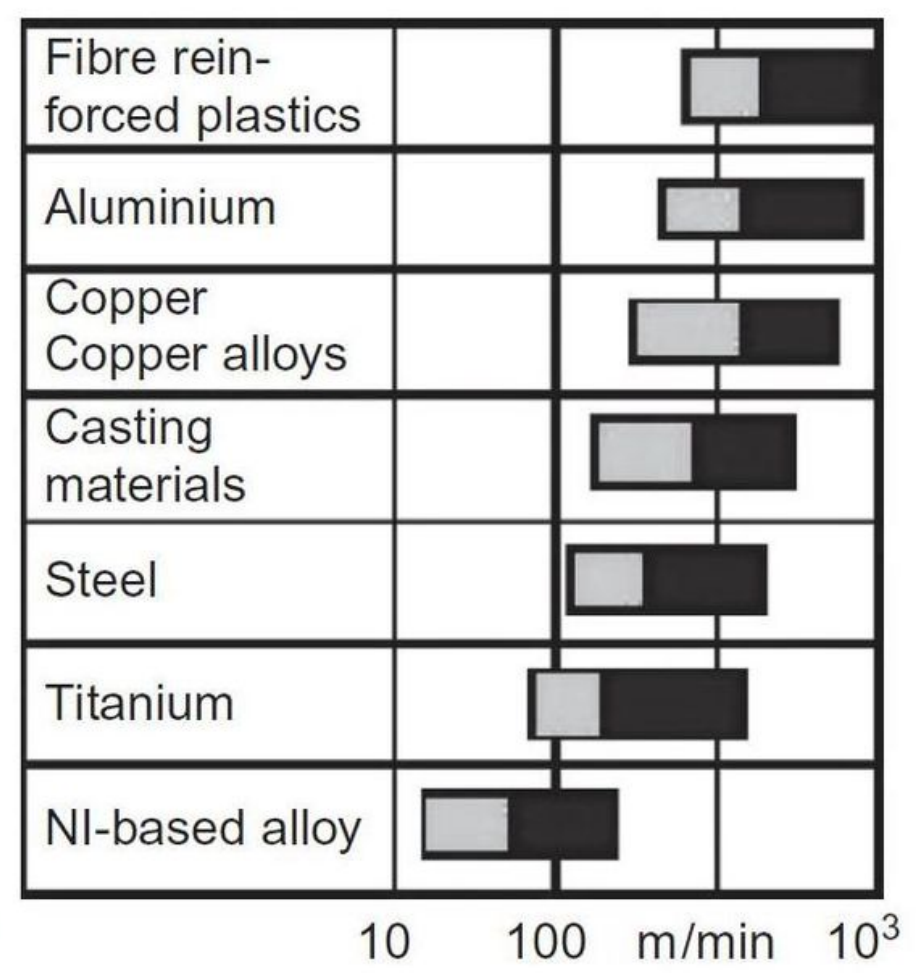

Figure 1

Achievable cutting speed depending on the type of machining operation (A) and work material (B) [6].

High-speed motor

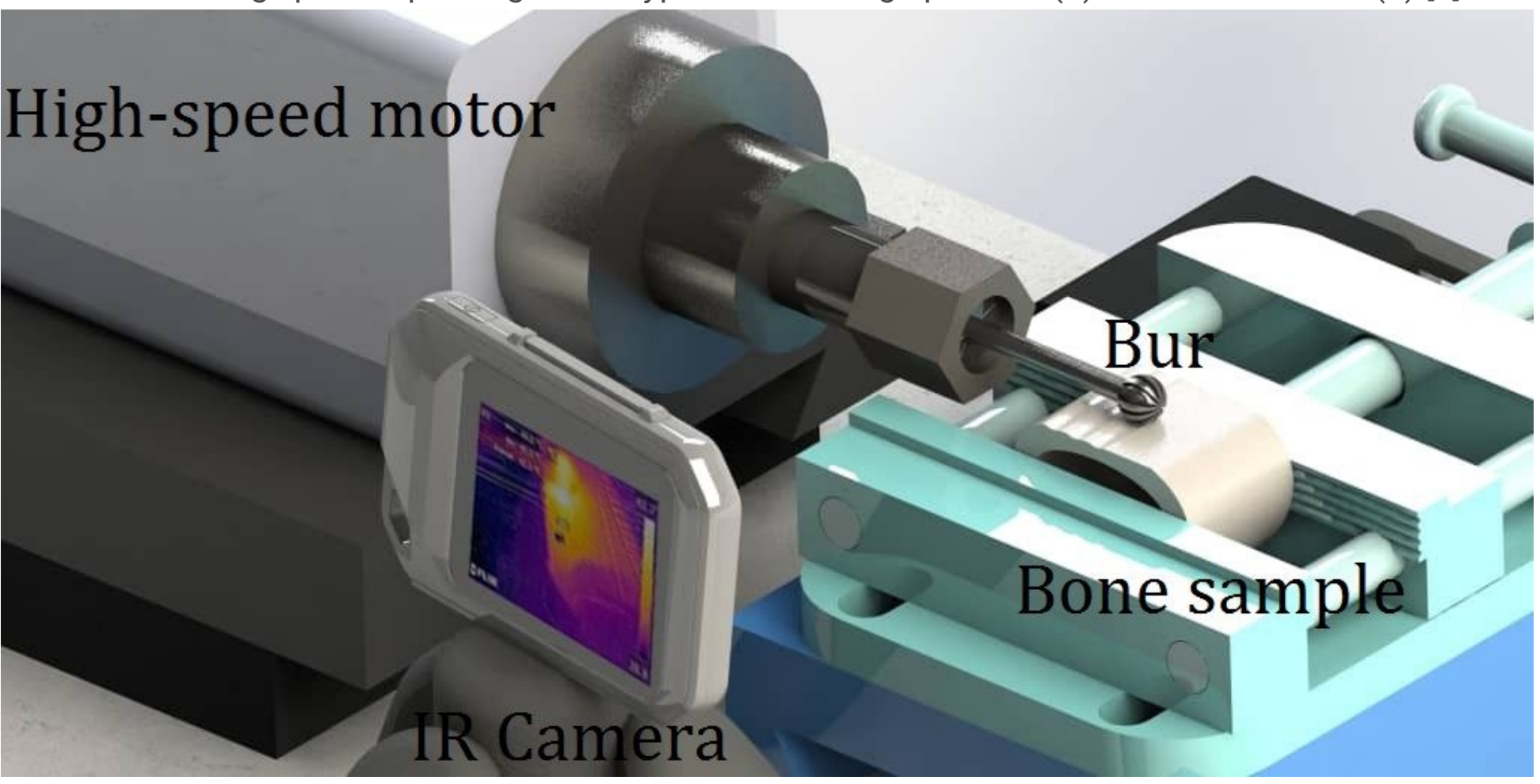

Figure 2 
A scheme of experimental setup of high-speed grinding of bone.

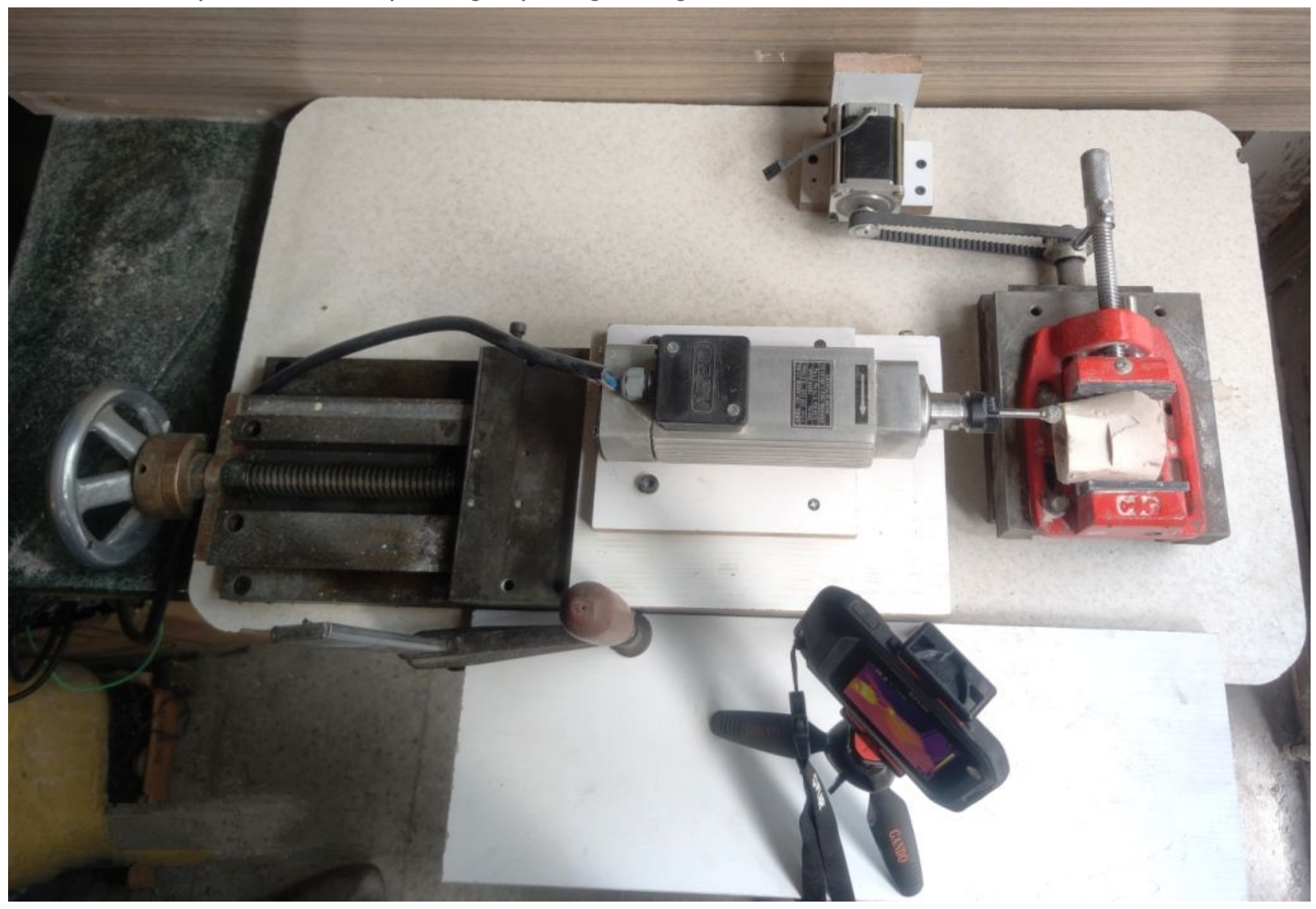

Figure 3

Experimentations of infrared thermography of high-speed grinding of bone. 


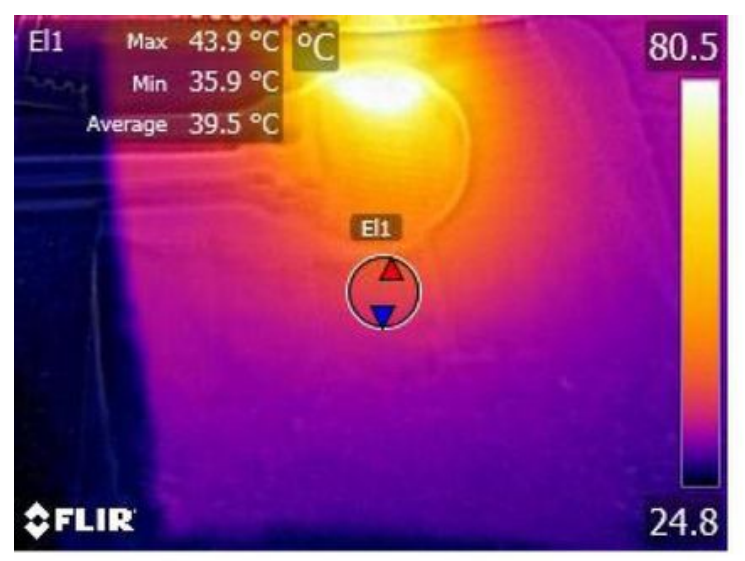

a $f=20 \mathrm{~mm} \cdot \mathrm{min}^{-1}, v=250 \mathrm{~m} \cdot \mathrm{min}^{-1}$

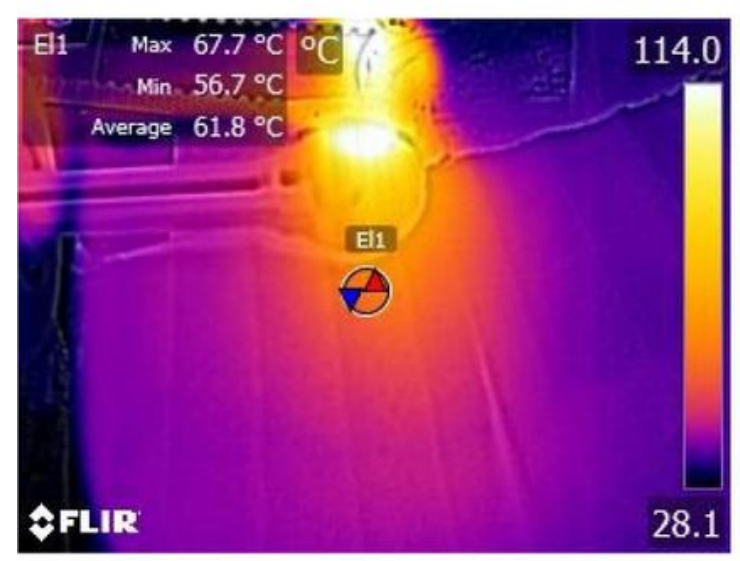

c $f=30 \mathrm{~mm} \cdot \mathrm{min}^{-1}, v=250 \mathrm{~m} \cdot \mathrm{min}^{-1}$

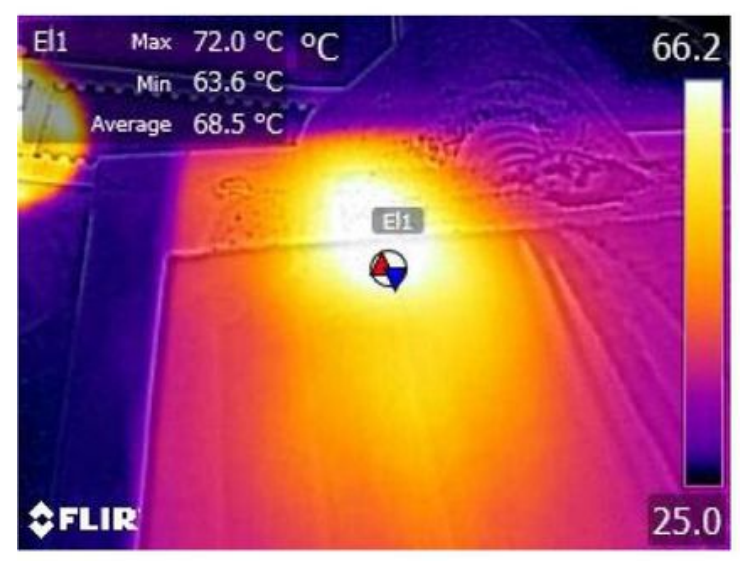

e $f=40 \mathrm{~mm} \cdot \mathrm{min}^{-1}, v=250 \mathrm{r} \cdot \mathrm{min}^{-1}$

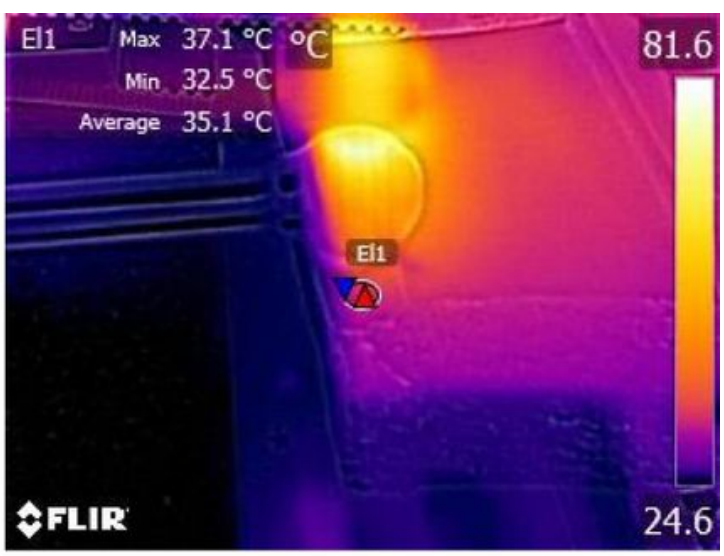

b $f=20 \mathrm{~mm} \cdot \mathrm{min}^{-1}, v=400 \mathrm{~m} \cdot \mathrm{min}^{-1}$

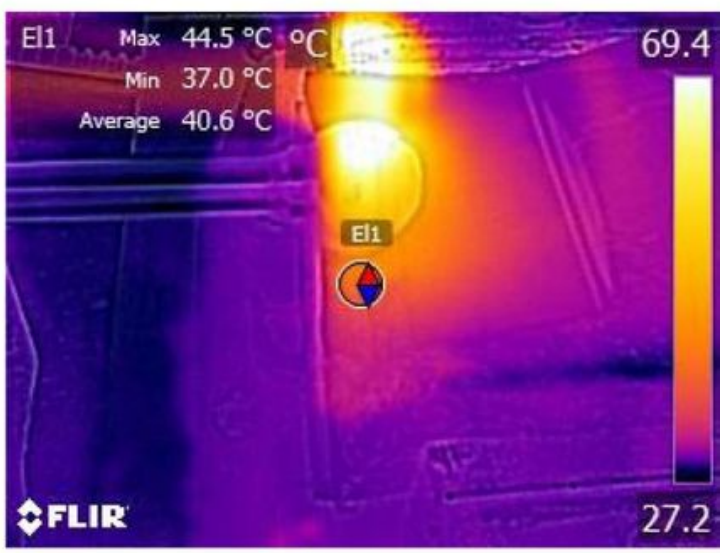

d $f=30 \mathrm{~mm} \cdot \mathrm{min}^{-1}, v=500 \mathrm{~m} \cdot \mathrm{min}^{-1}$

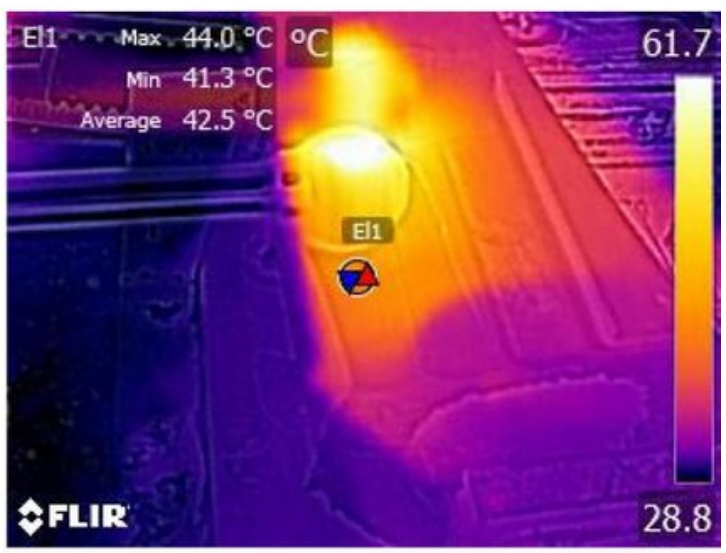

f $f=40 \mathrm{~mm} \cdot \mathrm{min}^{-1}, v=650 \mathrm{~m} \cdot \mathrm{min}^{-1}$

\section{Figure 4}

Thermographic images during high-speed grinding of bone in various feed rates. 


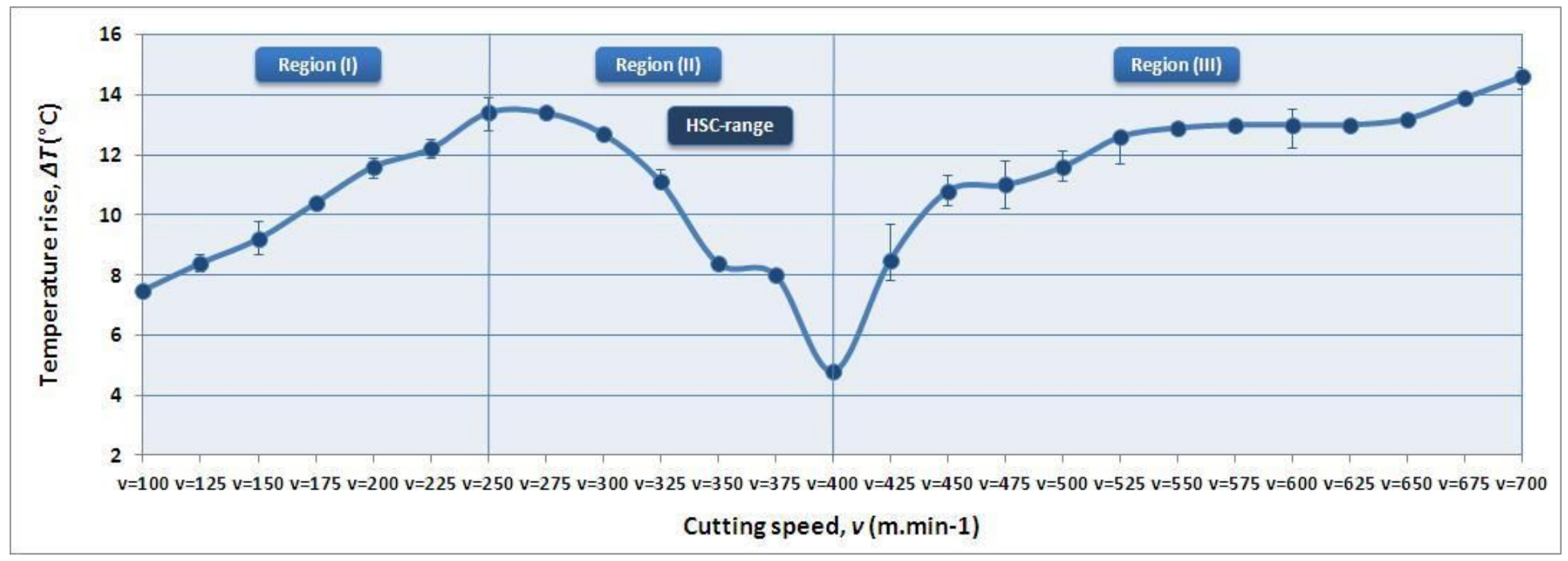

\section{Figure 5}

Temperature rise of bone, $\Delta T$, during high-speed grinding ( $f=20 \mathrm{~mm}$.min-1).

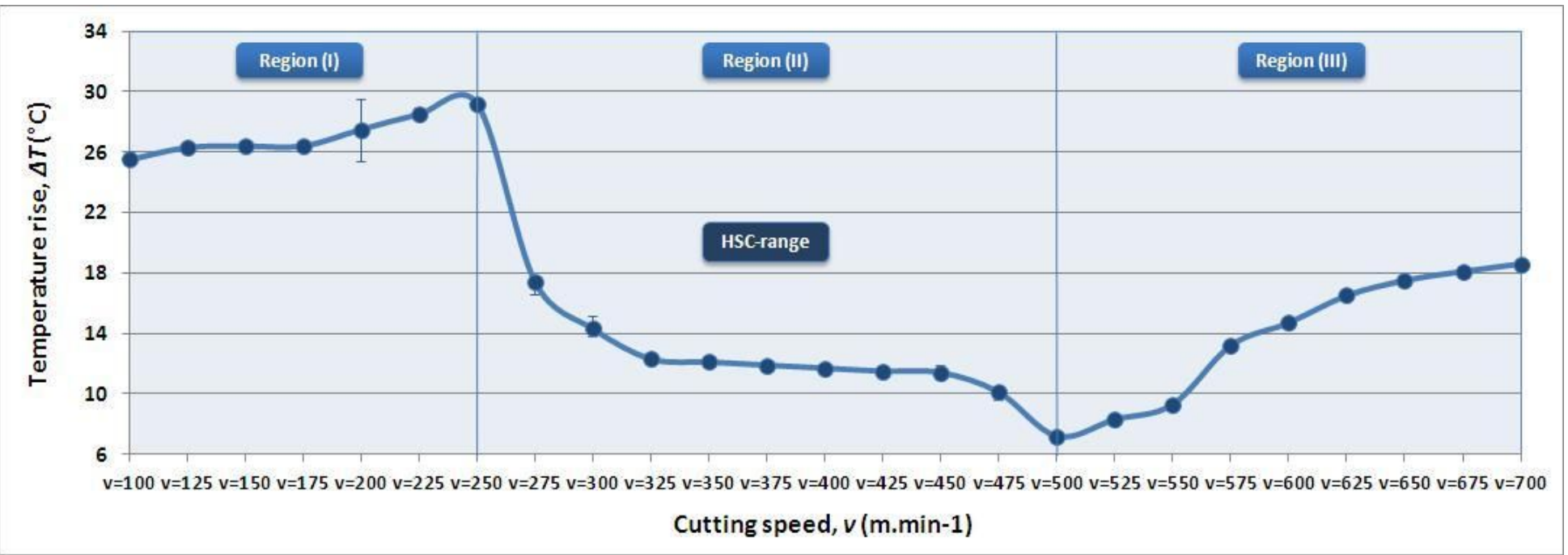

\section{Figure 6}

Temperature rise of bone, $\Delta T$, during high-speed grinding ( $f=30 \mathrm{~mm} \cdot \mathrm{min}-1)$. 


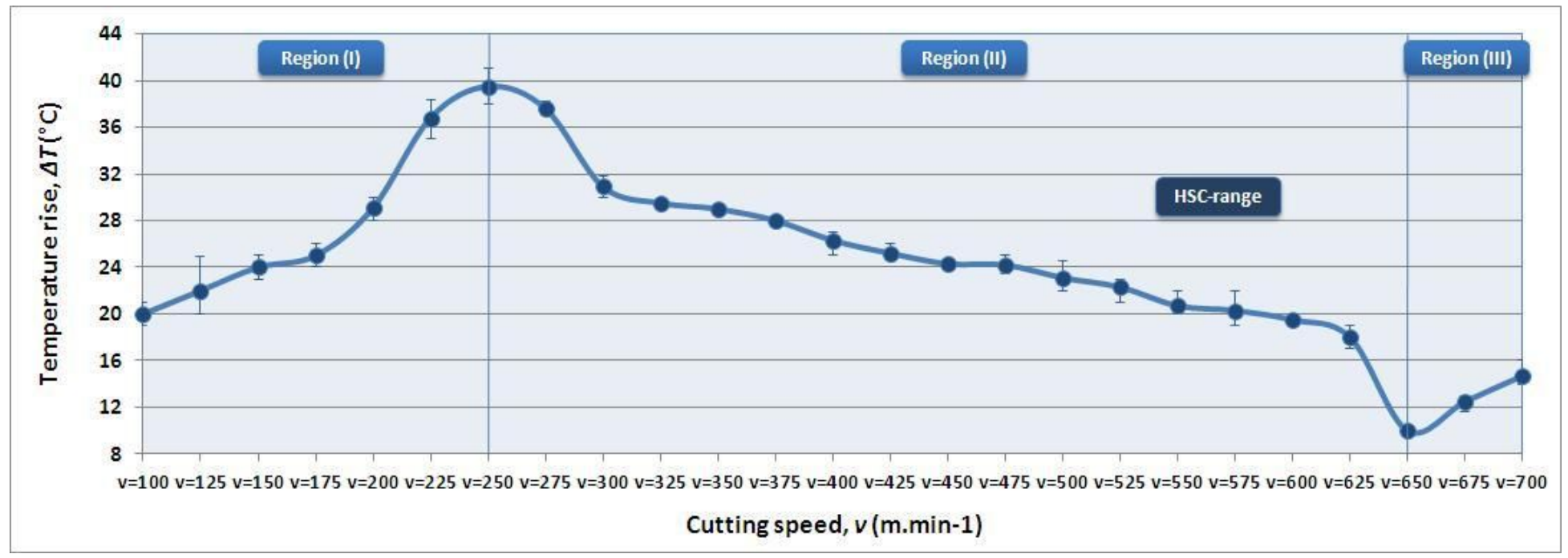

Figure 7

Temperature rise of bone, $\Delta T$, during high-speed grinding ( $f=40 \mathrm{~mm} \cdot \mathrm{min}-1)$.

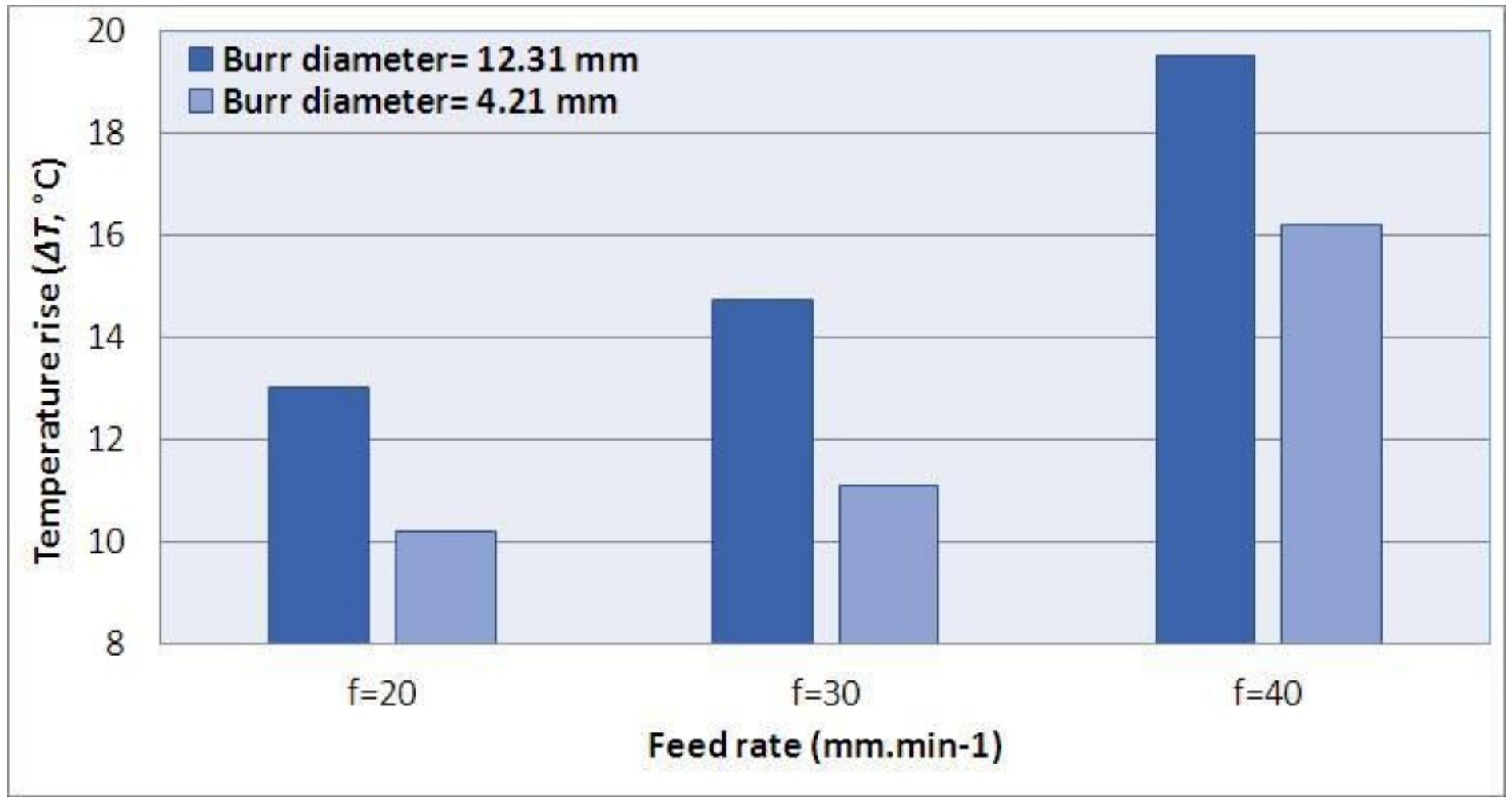

\section{Figure 8}

Comparison the results of the present study with research of Shakouri and Mirfallah [13] ( $v=600 \mathrm{~m}$.min-1, $\mathrm{d}=0.75 \mathrm{~mm})$.

\section{Supplementary Files}

This is a list of supplementary files associated with this preprint. Click to download. 
- Appendix.docx

Page 19/19 